\title{
SYMPOSIUM
}

\section{General Symposium}

J.BOGER (Convenor). Caregiver-centred design of gerontechnologies for supporting unpaid care in the community. Gerontechnology 2018;17(Suppl):20s; https://doi.org/10.4017/gt.2018.17.s.020.00 Participants O. ATOYEBI (CANADA), M. LESLIE (CANADA), and I. BOGER (CANADA). Issue Technology is playing an increasingly important role in supporting unpaid caregivers (e.g., family and friends); however, little work has been done to understand the specific needs, abilities, and preferences of caregivers, many of whom are older adults themselves. This symposium brings together expertise from the fields of engineering, human factors, computer science, qualitative methods, patient engagement, rehabilitation science, and gerontology to explore the implementation of different types of person-centered design approaches. The focus of the research that will be presented in the symposium is on the development of technologies to support unpaid caregivers of older adults living in the community. Content Presenters are investigators of the AGE-WELL National Centre of Excellence, a Canada-wide network for supporting research, knowledge translation, and commercialisation for technology and services to support older adults. O. Atoyebi will open the session with a discussion on developing user-centred technologies for improving the experience of family caregivers of those living with neurocognitive disorders. This discussion will cover the involvement of family caregivers in identifying potentially helpful technologies and developing preliminary prototype of the highest prioritized novel solutions to their specific needs. M. Leslie will then discuss the challenges and opportunities involved in achieving truly User-Centered-Design (UCD) when working with unpaid caregivers to create an assistive smartphone-based application. By describing the evolution of his own UCD process, Dr. Leslie's presentation will highlight methods for effectively engaging often-busy caregivers, and a goals-based approach to seeking optimal technology solutions for them. J. Boger will then conclude the presentations with an overview of the use of mixed-methods semi-structured interviews to ascertain features and functionality of the internet interface of CARE-RATE, a search tool for caregivers of people living with dementia. This will include a discussion of how perceived trustworthiness of the site can be captured and integrated into technology design. In addition to discussing their research, the presenters will highlight how outcomes have impacted work within AGE-WELL and beyond. Structure Participants will present an overview of their research for 20 minutes each followed by an open panel discussion between the participants and attendees. Conclusion The highlighted approaches and knowledge will provide symposium attendees with an overview of how technology can increasingly support community-dwelling caregivers. Attendees will also have the opportunity to discuss the benefits and challenges of employing UCD techniques to create gerontechnologies that meet user-identified needs and experiences.

Keywords: unpaid caregivers, technology design, person-centered design

Address: Department of Systems Design Engineering, University of Waterloo, Canada;

E: jboger@uwaterloo.ca 


\section{SYMPOSIUM}

\section{General Symposium}

O. ATOYEBI, F. ROUTHIER, M. PLANTE, C. AUGER, L. DEMER, J. FAST, A. WISTER, P. RUSHTON, J. LETTRE, M. BEAUDOIN, D. MALLETTE, B. MORTENSON. User-centred innovations for improving the experience of family caregivers of those living with neurocognitive disorders. Gerontechnology 2018;17(Suppl):21s; https://doi.org/10.4017/gt.2018.17.s.021.00 Purpose People with neurocognitive disorders (NCDs) often require informal care from relatives or friends who are referred to as family caregivers ${ }^{1}$. As the proportion of older persons in the Canadian population rises from $15.3 \%$ in 2013 to $25 \%$ by $2030^{2}$, more people are also being diagnosed with NCDs. For example, the number of people with dementia in Canada is expected to increase from 564,000 to 937,000 between 2016 and $2031^{3}$ and there will be an increasing need for people to care for older adults with $\mathrm{NCDs}^{4}$. Several caregivers experience physical, psychological, and social stress because of caregiving ${ }^{5}$. The burden on family caregivers is more pronounced because they are often in paid employment and must cope with the combined demands of work and informal care ${ }^{6}$. Previous studies on the technological needs of caregivers focused more on formal caregivers ${ }^{7}$; or were not specific for the needs of caregivers of people with $\mathrm{NCDs}^{8,9}$. Therefore, our objectives are to work collaboratively with caregivers of people with NCDs to prioritize novel solutions to make caregiving easier and more enjoyable to them, and to engage caregivers as part of a user-centred process to create a preliminary design of the highest ranked solution.

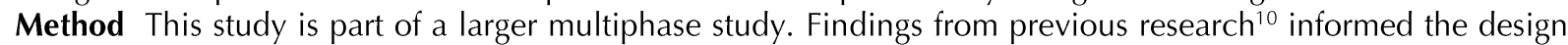
of an interview guide that was used in this qualitative study. We carried out in-depth interviews of 28 family caregivers providing care to a relative with NCD from British Columbia and Quebec; to determine their specific preferences in terms of technologies that would address their most pressing caregiving needs. Results \& Discussion We have suggested 37 devices, 8 programs and 4 policy changes as potential technological solutions to the specific needs of caregivers. These technologies include a smart cane that reminds the user to use it, and tracking systems that makes it easy to locate persons with NCDs and their household items. Based on these findings, we are developing a survey to collect quantitative data from family caregivers across Canada in which they will rank their preferences for 10 most prioritized technologies. In a final phase, we will work in focus groups with caregivers of people with NCDs and those they care for, to develop preliminary prototype of the highest prioritized novel solutions that they have identified.

\section{References}

1. Huber M, Rodrigues R, Hoffmann F, Gąsior K, Marin B. Facts and figures on long-term care for older people: Europe and North America. European Centre for Social Welfare Policy and Research, Vienna. 2009. Available from: http://www.euro.centre.org/data/LTC_Final.pdf

2. Statistics Canada. Population projections: Canada, the provinces and territories, 2013 to 2063. Statistics Canada, Ottawa. 2014. Available: www.statcan.gc.ca/daily-quotidien/140917/dq140917a-eng.htm

3. Alzheimer Society of Canada. Prevalence and Monetary Costs of Dementia in Canada. Toronto. Alzheimer Society of Canada. 2016

4. Williams AM, Wang L, Kitchen P. Differential impacts of care-giving across three caregiver groups in Canada: end-of-life care, long-term care and short-term care. Health \& social care in the community. 2014 Mar 1;22(2):187-196

5. Semiatin AM, O'Connor MK. The relationship between self-efficacy and positive aspects of caregiving in Alzheimer's disease caregivers. Aging \& Mental Health. 2012 Aug 1;16(6):683-688

6. Sinha M. Portrait of caregivers, 2012. Ottawa: Statistics Canada; 2013 Sep 10

7. Topo P. Technology studies to meet the needs of people with dementia and their caregivers: a literature review. Journal of applied Gerontology. 2009 Feb;28(1):5-37

8. AARP. Caregivers \& Technology: What They Want and Need. A Guide for Innovators - Research from A Nationally Representative Sample of America's 40 Million Family Caregivers. 2016

9. Mortenson WB, Demers L, Fuhrer MJ, Jutai JW, Lenker J, DeRuyter F. How assistive technology use by individuals with disabilities impacts their caregivers: a systematic review of the research evidence. American Journal of Physical Medicine \& Rehabilitation. 2012 Nov 1;91(11):984-998

10. Mortenson WB, Pysklywec A, Fuhrer MJ, Jutai JW, Plante M, Demers L. Caregivers' experiences with the selection and use of assistive technology. Disability and Rehabilitation: Assistive Technology. 2017 Jul 27:1-6

Keywords: technology, aging, family caregivers, Neurocognitive disorders, Dementia

Address: GF Strong Rehab Res Lab, University of British Columbia;

E: ben.mortenson@ubc.ca 


\section{SYMPOSIUM}

\section{General Symposium}

M. LESLIE. Evolving how we design gerontechnology software: User-centered-design in action on the development of a caregiver support tool. Gerontechnology 2018;17(Suppl):22s; https://doi.org/10.4017/gt.2018.17.s.022.00 Purpose This paper takes an alternative perspective on the central theme of the 2017 International Society for Gerontechnology World Conference. Where the conference theme focuses on "Evolving Designs for our Future Selves," the paper uses experiences from ongoing research to argue that, as a field, we need to evolve how we go about designing gerontechnology to support caregivers. The User-Centred Design (UCD) approach to software development is three decades old and as such a robust literature describing the aims, methods, and ethics of engaging end-users has emerged ${ }^{1-3}$. Similarly, engagement - whether of the public generally, or specifically of patients and clinicians - has become a watchword in the development and deployment of Health Technology at hospital and system levels ${ }^{4}$. In this broader context of UCD and engagement in software and technology design, the particular challenges of gerontechnology development have received little attention. This talk uses a case study of a gerontechnology development project aimed at creating a smartphone application to assist the informal or family caregivers who supply the majority of care to the elderly ${ }^{5}$. Method Funded by Canada's AGEWELL, National Centre for Excellent, this project initially went into the field seeking to deploy two well-established methods for engaging, consulting, prioritizing, and co-designing with end-user caregivers. Specifically, we intended to use Citizen Panels, Delphi methods and Design Thinking methods to develop an application that would assist caregivers where they felt they could most use help. As the talk will show, this intended methodology was, in practice, neither user centered, nor patient engaged. Working with critiques and assistance from our community partner, as well as the support of our funder, we have modified our methods and extended our timeline to ensure user centrism and high quality engagement. Results \& Discussion Through descriptions of our interactions with our community partner, and ongoing recruitment efforts, the talk highlights how we have evolved our approach to engagement and consultation (Citizen Panel), prioritization (Delphi), and co-design (Design Thinking) to meet the on-the-ground realities of caregivers' lives, and our desire to follow collaborative, dialogic development principles ${ }^{2}$. Specifically, the evolution of the project's methods has seen us abandon the large group, residential Citizen Panel format linked to an online Delphi process. Instead, we are now convening small group, non-residential Nominal Group Technique sessions in which consultation and prioritization take place over the course of two in-person events. In addition to making changes that accommodate caregivers' schedules, this evolution in methods has led to a new emphasis on identifying end users' goals, rather than needs. This has, in turn, allowed us to begin unpacking the issues of trust and time commitment that are foundational to creating an application that caregivers will adopt and use in the long term.

\section{References}

1. Endsley MR. Designing for situation awareness : an approach to user-centered design. 2nd ed. Boca Raton, FL: CRC Press; 2011

2. Salvo MJ. Ethics of Engagement: User-Centered Design and Rhetorical Methodology. Technical Communication Quarterly. 2001;10(3):273-290

3. Holtzblatt K, Wendell JB, Wood S. Rapid contextual design : a how-to guide to key techniques for usercentered design. San Francisco: Elsevier/Morgan Kaufmann; 2005

4. Gagnon MP, Desmartis M, Gagnon J, et al. Framework for user involvement in health technology assesstment at the local level: Views of health managers, user representatives, and clinicians. International journal of technology assessment in health care. 2015;31(1-2):68-77

5. Keating NC, Fast JE, Lero DS, Lucas SJ, Eales J. A taxonomy of the economic costs of family care to adults. The Journal of the Economics of Ageing. 2014;3:11-20

Keywords: user centered design, caregivers

Address: $546-9068^{\text {th }}$ Avenue SW, Calgary, AB T2P 1H9, Canada;

E: myles.leslie@ucalgary.ca 


\section{SYMPOSIUM}

\section{General Symposium}

P. CHAUHAN, J. BOGER, T. HUSSEIN, S. MOON, F. RUDZICZ, I. POLGAR. Creating the CARE-RATE interfaCe through multi-modal participatory design with caregivers of people with dementia. Gerontechnology 2018;17(Suppl):23s; https://doi.org/10.4017/gt.2018.17.s.023.00 Over 5.5 million Americans are living with dementia and this number is expected to rise to 16 million by $2050^{1}$. Family and other unpaid caregivers (e.g., friends) of people with dementia provide much of the required support. An estimated 15 million people provided approximately 18.2 billion hours of unpaid hours of care in the United States alone ${ }^{1}$. While the internet has many resources that can help (e.g., information, community programs, products, etc.), caregivers often do not know what they are looking for, how to find it, or how to assess the validity of resource when they find it. CARE-RATE is an online tool being created to enable caregivers living in the community to find and evaluate resources for supporting people with dementia. Caregivers use plain language to describe the situation they are facing to CARE-RATE, which then leverages artificial intelligence to have an on-screen dialogue with the caregiver to capture context-specific information. This information is then used to search the web for products, strategies, and local resources that fit the individualized needs of the person doing the search. As many family caregivers of people with dementia can be overwhelmed with their responsibilities or older adults themselves, it is important that the user interface is designed in a way that supports caregiver abilities and preferences so that interacting with CARE-RATE is as intuitive as possible. Little work has been done into interface design for caregivers of people with dementia, therefore this research focused on determining what design layout and features would be preferred by potential users. Method Results from previous focus groups ${ }^{2}$ were used to create three different CARE-RATE interface designs (i.e., wireframes) (Figure 1). A randomised mixed-methods semi-structured interview process was used to assess design features with family caregivers $(n=6)$. Features were grouped into different categories: (1) design aesthetics, (2) navigation, (3) ease of use, (4) trustworthiness of information, (5) learnability, and (6) likelihood of using the tool if they encountered it while browsing the internet. Results $\&$ Discussion Five participants preferred the search bar design with one equally preferring the tree flowchart. The search bar was also rated as the most appealing and trustworthy-looking, with participants mentioning that they liked its simplicity and similarity in appearance to other search engines on the internet. The tree flowchart was ranked second and chatbot last, with participants expressing concern about the possible misconception they may be chatting with a human. Participants also had strong opinions regarding the importance of the perception of trust toward online sites, which included credibility of information, what the site looks like, source of the information, affiliations with known and trusted organisations, and the ability to contact the information's host. These and other results will inform the CARE-RATE interface design, which will be evaluated in the next phase of research by family caregivers living in the community.

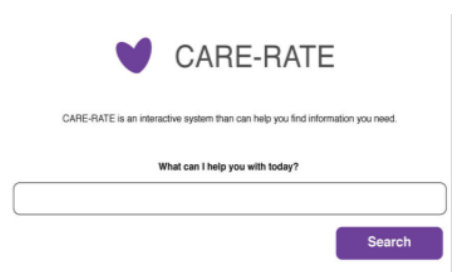

(a)

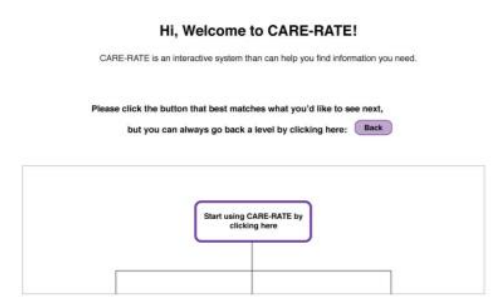

(b)

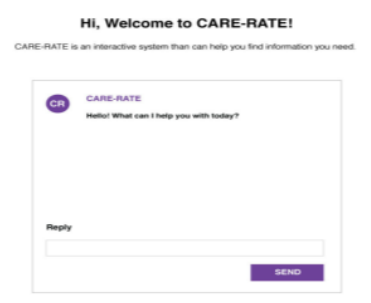

(c)

Figure 1. Examples of wireframe designs for the (a) search bar, (b) tree flowchart, and (c) chatbot

\section{References}

1. Alzheimer's Association. 2017 Alzheimer's Disease Facts and Figures. 2017. Report No.:13:325-373.

2. Boger J, Rudzicz F, Chinaei H, Jónasdóttir SK, Wambua M, Polgar J. CARE-RATE: Initial development of an artificially intelligent online tool for connecting caregivers to relevant support. RESNA, 2017 Jun 28-30; New Orleans, LA.

Keywords: dementia, caregiver, online support, artificial intelligence Address: University of Waterloo, Canada;

E: jboger@uwaterloo.ca 